\title{
A small molecule inhibitor of XIAP induces apoptosis and synergises with vinorelbine and cisplatin in NSCLC
}

\author{
EJ Dean ${ }^{1,2}$, T Ward', C Pinilla ${ }^{3}$, R Houghten ${ }^{3}, K$ Welsh $^{4}$, G Makin', M Ranson ${ }^{2}$ and C Dive ${ }^{*, 1}$ \\ 'Department of Clinical and Experimental Pharmacology, Paterson Institute for Cancer Research, University of Manchester, Wilmslow Road, Manchester \\ M20 4BX, England, UK; '² Derek Crowther Unit, Christie Hospital NHS Foundation Trust, Wilmslow Road, Manchester M20 4BX, England, UK; \\ ${ }^{3}$ Torrey Pines Institute for Molecular Studies, 3550 General Atomics Court, 2-129, San Diego, CA 92121 - I I 22, USA; ${ }^{4}$ Burnham Institute for Medical \\ Research, La Jolla, CA 92037, USA
}

BACKGROUND: Evasion of apoptosis contributes to the pathogenesis of solid tumours including non-small cell lung cancer (NSCLC). Malignant cells resist apoptosis through over-expression of inhibitor of apoptosis proteins (IAPs), such as X-linked IAP (XIAP). METHODS: A phenylurea-based small molecule inhibitor of XIAP, XIAP antagonist compound (XAC) I396-I I, was investigated preclincally to determine its ability to sensitise to clinically relevant cytotoxics, potentially allowing dose reduction while maintaining therapeutic efficacy.

RESULTS: XIAP protein expression was detected in six NSCLC cell lines examined. The cytotoxicity of XAC I 396- I I against cultured NSCLC cell lines in vitro was concentration- and time-dependent in both short-term and clonogenic assays. XAC I396- I I-induced apoptosis was confirmed by PARP cleavage and characteristic nuclear morphology. XAC I396-II synergised with vinorelbine \pm cisplatin in $\mathrm{H} 460$ and A549 NSCLC cells. The mechanism of synergy was enhanced apoptosis, shown by increased cleavage of caspase-3 and PARP and by the reversal of synergy by a pan-caspase inhibitor. Synergy between XAC I396- II and vinorelbine was augmented by optimising drug scheduling with superior effects when XAC I396-II was administered before vinorelbine.

CONCLUSION: These preclinical data suggest that XIAP inhibition in combination with vinorelbine holds potential as a therapeutic strategy in NSCLC.

British Journal of Cancer (2010) I 02, 97-103. doi:I0.1038/sj.bjc.66054I8 www.bjcancer.com

Published online 10 November 2009

(c) 2010 Cancer Research UK

Keywords: XIAP antagonist compound; XIAP; XAC I396-I I; apoptosis, non-small cell lung cancer (NSCLC)

Lung cancer is the leading cause of cancer deaths among men and women. In the United Kingdom, lung cancer accounts for $22 \%$ of total cancer deaths with only a $7 \% 5$-year survival (CR-UK, 2009). The major histological types of lung cancer are small cell lung cancer (SCLC), adenocarcinoma, squamous carcinoma and large cell carcinoma, the latter three of which are collectively referred to as non-small cell lung cancer (NSCLC). NSCLC represents approximately $80 \%$ of all cases and chemotherapy, most commonly consisting of a platinum agent in combination with another cytotoxic such as gemcitabine, vinorelbine or a taxane, can provide palliation and prolong survival (Spira and Ettinger, 2004). Despite encouraging progress with novel targeted agents, for example, erlotinib and bevacizumab, mortality rates remain dismal as over two-thirds of patients are diagnosed with advanced, metastatic disease for which no curative treatment is currently available.

One hallmark of cancer is evasion of apoptosis (Hanahan and Weinberg, 2000). Cancer cells are assumed to be under continuous pro-apoptotic stresses from genetic instability and their hostile microenvironment (oxygen and nutrient deprivation), but selected

*Correspondence: Professor C Dive; E-mail: cdive@picr.man.ac.uk Revised 5 October 2009; accepted 8 October 2009; published online 10 November 2009 cell subpopulations adapt and de-couple these genetic and microenvironmental stress stimuli from commitment to apoptosis. The development of apoptosis-targeted therapies aims to lower the threshold for apoptosis but it is not yet clear whether these agents will be effective alone or in combination with chemotherapy or radiation (Reed, 2003).

One mechanism by which cells resist apoptosis is the overexpression of inhibitor of apoptosis protein (IAP) family of proteins. Although IAP proteins have shown diverse roles, it is their unique ability to inhibit distinct caspases that drive apoptotic cell death that has driven research exploring their therapeutic potential (Deveraux et al, 1997). Eight human IAPs have been identified of which X-linked IAP (XIAP) protein is the best characterised and most potent, inhibiting caspases-3 and -7 through its BIR2 domain (Scott et al, 2005) and caspase-9 through its BIR3 domain (Deveraux et al, 1997). To ensure cells commit to apoptosis when appropriately damaged, cells also use endogenous antagonists of XIAP (including SMAC, HtrA2/Omi, ARTS and XAF1) (Srinivasula et al, 2001b). These act by preventing XIAP binding to caspases ( $\mathrm{Du}$ et al, 2000; Verhagen et al, 2000) or by triggering its redistribution from the cytosol to the nucleus (Liston et al, 2001). XIAP is considered to be a valid therapeutic target in malignancy because firstly it is over-expressed in the majority of a panel of NCI tumour cell lines (Tamm et al, 2000); secondly, XIAP over-expression correlates with resistance to 
apoptosis through stimulation of both the intrinsic (mitochondrial directed) and extrinsic (death receptor directed) pathways (Holcik et al, 2000; Wilkinson et al, 2004); thirdly, downregulation of XIAP with siRNA or antisense oligonucleotides (ASOs) restores chemosensitivity in various tumour cell lines (Sasaki et al, 2000; McManus et al, 2004); and finally, XIAP knockout mice have normal survival with no significant pathological features (Harlin et al, 2001), consistent with XIAP-targeted therapeutics exerting minimal toxicity to normal tissues.

XIAP inhibition, using small molecule inhibitors (SMIs) that target XIAP baculovirus (BIR) domains, gained momentum after the discovery of short polypeptides based on endogenous inhibitor SMAC, which are capable of selective BIR3 inhibition (Li et al, 2004; Oost et al, 2004). Subsequently, di- and tri-phenylurea-based XIAP antagonist compounds (XACs) that bind near the BIR2 domain have also been identified by combinatorial chemical library screening (Wang et al, 2004; Schimmer et al, 2004a). These XACs, but not inactive structural analogs, induced apoptosis directly in several haematologic and solid tumour cell lines in vitro, and sensitised cancer cells to chemotherapeutic drugs (Berezovskaya et al, 2005; Carter et al, 2005; Kater et al, 2005). Active compounds also suppressed the growth of established xenografts while displaying little toxicity (Karikari et al, 2007). Here, XAC 1396-11, a phenylurea-based SMI of XIAP (that targets near the BIR2 domain), was investigated as a potential therapy for NSCLC. The effect of XAC 1396-11 as a single agent and in combination with clinically relevant cytotoxic drugs was explored in vitro. The importance of optimising treatment schedule when inhibiting XIAP is shown, showing that treatment effects are, in part, dependent on when the 'apoptotic brake' is removed in relationship to a cytotoxic insult. These results suggest that XIAP inhibition with XAC 1396-11 holds promise as a therapeutic strategy in the treatment of NSCLC and that further studies are warranted.

\section{MATERIALS AND METHODS}

\section{Human NSCLC cell lines}

Human NSCLC cell lines H460, A549, H520, HCC827, H522 and HCT116 were obtained from the American Type Culture Collection (Manassas, VA, USA). MGH-4 and HCT116 XIAP-/- were kind gifts from Dr M-S Tsao (Princess Margaret Hospital, Toronto) and Dr B Vogelstein (Johns Hopkins University School of Medicine, MD, USA), respectively. All cells lines were maintained in RPMI 1640 supplemented with $10 \%$ fetal bovine serum.

\section{Reagents and chemicals}

XAC 1396-11 was synthesised and purified as described (Schimmer et al, 2004b), and dissolved in DMSO for in vitro assays. All cytotoxics were purchased from Sigma-Aldrich (Gillingham, UK), except for gemcitabine (Eli Lilly, Basingstoke, UK). The pancaspase inhibitor (Caspase Inhibitor III) was obtained from Calbiochem (Merck Chemicals Ltd, Nottingham, UK).

\section{Cell cytotoxicity}

The sulforhodamine B (SRB) assay was used to determine cell population number in response to XAC 1396-11. NSCLC cell lines were plated in exponential growth phase in 96-well plates and treated with varying concentrations of XAC 1396-11. At various times, thereafter, cells were fixed and stained according to standard SRB protocol (Vichai and Kirtikara, 2006), and absorbance was measured using a microplate reader (Labsystems Multiskan EX, (Thermo Scientific, Milford, MA, USA) at $540 \mathrm{~nm}$. Nuclear apoptotic morphology was assessed by UV-microscope examination of fixed cells stained with DAPI. Treated cells were trypsinised and re-suspended in PBS. The samples were cytospun onto slides at 500 r.p.m. for $5 \mathrm{~min}$ before fixing in $1 \%$ formaldehyde in PBS-T. The slides were washed in PBS-T and the cells stained with ProLong Gold antifade reagent with DAPI (Invitrogen, Paisley, UK). Slides were analysed by fluorescence microscopy $(358 / 461 \mathrm{~nm})$ using an Olympus BX51.

\section{Clonogenic assay}

Cells were plated at 200 per well in six-well tissue culture plates (Costar, Corning, NY, USA) and allowed to attach overnight. Cells were treated with varying concentrations of XAC 1396-11 for $24 \mathrm{~h}$, before the medium was aspirated, cells washed with PBS and fresh medium added. Plates were kept in a tissue culture incubator at $37^{\circ} \mathrm{C}$ and $5 \% \mathrm{CO}_{2}$ for 7 days to allow colony growth. Colonies were fixed with $70 \%$ methanol and stained with methylene blue, and colonies ( $>50$ cells) were counted. All assays were performed in triplicate. Surviving fraction was calculated as number of colonies in the test condition/number of colonies in the untreated well and plotted logarithmically against drug concentration.

\section{Immunoblot assay}

For immunoblot analysis, cells were treated with XAC 1396-11 or with vehicle control for various times. Protein lysates were prepared using lysis buffer $(10 \times)$ (Cell Signalling Technology, Danvers, MA, USA) and protease inhibitor cocktail (SigmaAldrich). All samples were sonicated at $10 \mathrm{~Hz}$ for $10 \mathrm{~s}$. Protein lysates were resolved by electrophoresis in appropriate percentage polyacrylamide gels and transferred to PVDF membranes (Immobilon, Millipore, Watford, UK). Standard immunoblotting procedures were followed with overnight incubation at $4{ }^{\circ} \mathrm{C}$ with the following primary antibodies: XIAP 1:1000 (BD Transduction Laboratories, Oxford, UK), cIAP-1 1:1000 (R\&D Systems, Minneapolis, MN, USA), cIAP-2 (R\&D Systems), Survivin (Novus Biologicals, Littleton, CO, USA), SMAC 1:1000 (BD Transduction Laboratories), XAF1 1:1000 (Imgenex, San Diego, CA, USA) and PARP (Cell Signalling). Blots were visualised with the enhanced chemiluminescence system (Amersham, Chalfont St Giles, UK) and analysed using a Fuji LAS-1000 Plus imaging system with AIDA software (Fuji, Bedford, UK). The proportion of cleaved caspase-3 was measured using the Meso Scale Discovery MULTISPOT Cleaved/Total Caspase-3 Assay.

\section{Drug combination assays}

The combination index (CI) method was used to determine multiple drug-effect interaction using the computer software CalcuSyn (Biosoft, Cambridge, UK). The method is based on the multiple drug-effect equation of Chou-Talalay derived from enzyme kinetic models (Chou and Talalay, 1977) in which values for drug additivity are in the range $\mathrm{CI}=0.9-1.1$ and values for synergy and antagonism are $<0.9$ and $\mathrm{CI}>1.1$, respectively. The ratios of XAC 1396-11 and cytotoxic drugs were fixed using $\mathrm{IC}_{50}$ values from the SRB assay. Cells were co-treated for $72 \mathrm{~h}$ using XAC 1396-11 and various cytotoxic drugs. Six drug concentrations were used covering the concentration-effect. Linear correlation coefficients $(r)$ were generated for each concentration response curve to determine the applicability of the data to the method of analysis. To confirm the synergistic drug interactions identified by $\mathrm{CI}$ analysis, the three-dimensional (3D) response surface model of Pritchard and Shipman (Pritchard and Shipman, 1990) was applied. The 3D method is based on a five by eight 'checkerboard' matrix (40 data points) of XAC 1396-11/cytotoxic drug combinations plus each drug tested alone, covering the concentrationeffect curve. Data from the SRB assay, performed in triplicate, were used to calculate theoretical (individual dose responses) and experimental surfaces (drug combinations minus 2 s.d.). The theoretical surface is then subtracted from the experimental 
surface to reveal regions of synergy (above the baseline) and antagonism (below the baseline). Positive values are summed together to give the overall synergy value $\left(\mu \mathrm{M}^{2} \%\right)$ across the response surface at the $95 \%$ confidence interval.

\section{Statistics}

Statistical significance for a change in percentage cells with nuclear apoptotic morphology was determined by two-tailed paired $t$-tests (assuming equal variance) between the drug combination counts and the single agents.

\section{RESULTS}

\section{IAPs are widely expressed in NSCLC cell lines}

Immunoblot analysis of a panel of NSCLC cell lines confirmed that XIAP is widely expressed at levels comparable with the colon cancer cell lines HCT116, known to express XIAP at a level above the average reported for the NCI 60 tumour cell line panel (Figure 1) (Tamm et al, 2000). Additionally, cIAP-1, cIAP-2, Survivin and SMAC were also expressed in the NSCLC lines tested, albeit with levels varying among cell lines.

\section{XAC 1396-11 induces apoptotic cell death in a time- and concentration-dependent manner in NSCLC cell lines}

XAC 1396-11 caused concentration-dependent growth inhibition in $\mathrm{H} 460$, A549, H520 and MGH-4 cell cultures (shown for H460 and A549 in Figure 2A), as measured by the SRB assay. The $\mathrm{IC}_{50}$ for a $72 \mathrm{~h}$ drug challenge was 2.8 and $4.0 \mu \mathrm{M}$ for $\mathrm{H} 460$ and A549 cells, respectively. In both of these cell lines, a $1 \mathrm{~h}$ drug exposure had minimal effect on growth inhibition but by $24 \mathrm{~h}$, near maximal effect was observed. Similar growth inhibition was observed at 48- and $72 \mathrm{~h}$ exposure to XAC 1396-11.

The long-term effects of XAC 1396-11 were assessed by clonogenic assay (Figure $2 \mathrm{~B}$ ). The clonogenic $\mathrm{IC}_{50}$ values after $24 \mathrm{~h}$ XAC 1396-11 treatment were 4.5 and $7.8 \mu \mathrm{m}$ for $\mathrm{H} 460$ and A549 cells, respectively, showing higher sensitivity for H460 cells consistent with the SRB assay.

Analysis of the levels of cleaved PARP in XAC 1396-11-treated H460 cells confirmed time- and concentration-dependent activation of endogenous caspases, suggesting that the observed cell loss occurred by apoptosis (Figure 2C). To provide further confirmatory evidence of apoptotic cell fate, H460 cells treated in both a time- and concentration-dependent manner were also stained with DAPI to reveal nuclear morphology. Concentrations of XAC 1396$11 \geqslant 7.5 \mu \mathrm{M}$ were sufficient to induce apoptotic morphology after $24 \mathrm{~h}$ drug exposure (Figure 2D upper panel). Increased apoptotic indices were evident as early as $16 \mathrm{~h}$ after treatment with $10 \mu \mathrm{M}$ XAC 1396-11 (Figure 2D, lower panel).

\section{XAC 1396-11 synergises with cytotoxic anticancer drugs in NSCLC lines}

Pre-clinical data on apoptosis-targeted agents suggest that their ultimate clinical use will be in combination with cytotoxics, in which an enforced reduction in the cellular threshold for apoptosis by the former should sensitise to the latter. Therefore, the effects of XAC 1396-11 in combination with a variety of chemotherapeutics that are conventionally used in NSCLC were explored using the CI and Pritchard and Shipman methods. Table 1 shows the CI values derived from treatment with XAC 1396-11 and various cytotoxic anticancer drugs. XAC 1396-11 showed synergy with vinorelbine, cisplatin and gemcitabine in both $\mathrm{H} 460$ and A549 cell lines. However, the combination of XAC 1396-11 with taxotere was not synergistic. Particularly, striking was the synergy at $\mathrm{IC}_{25}, \mathrm{IC}_{50}$ and $\mathrm{IC}_{75}$ observed for the combination of XAC 1396-11 and vinorelbine
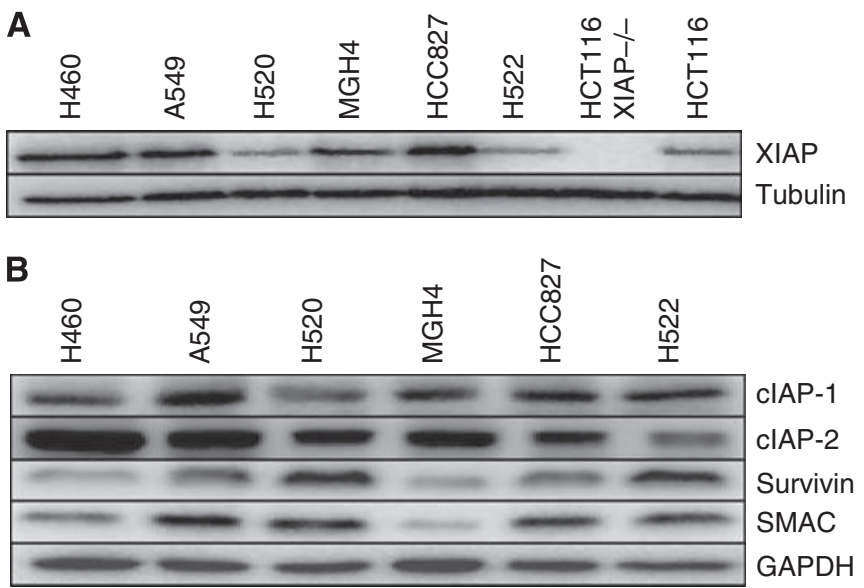

Figure I Immunoblot analysis of IAP family members in NSCLC lines. (A, B) Cell lysates were prepared from cell lines, normalised for total protein content ( $15 \mu \mathrm{g}$ per lane), and analysed by SDS-PAGE using antibodies recognising XIAP, c-IAPI, c-IAP2, Survivin and SMAC. Tubulin or GAPDH was used as a protein loading control. Data are representative of $n=3$ independent repeat experiments.

in both the H460 and A549 cell lines after $72 \mathrm{~h}$ co-administration. Synergy was also noted in the concentration-effect graph (Figure 3C) as a left shift for the combination treatment, that is the surviving fraction is less for the combination using the same concentrations compared with single drug treatments. In $\mathrm{H} 460$ cells, the XAC 1396-11/vinorelbine combination was also synergistic at 24 and $48 \mathrm{~h}$ drug exposure (data not shown). Further confirmatory evidence of synergy between XAC 1396-11 and vinorelbine was shown using the Pritchard and Shipman method. Figures $3 \mathrm{~A}$ and $\mathrm{B}$ show the $3 \mathrm{D}$ checkerboard plots from combining 5 dilutions of XAC 1396-11 (dilution factor 1.5 in H460 cells, 1.3 in A549) with 8 dilutions of vinorelbine (dilution factor 1.3 in both cell lines). The most synergistic concentrations were $2.2 \mu \mathrm{m}$ XAC 1396-11 and 3.4 nM vinorelbine in $\mathrm{H} 460$ cells, and $2.5 \mu \mathrm{M} \mathrm{XAC}$ 1396-11 and 3.6 nM vinorelbine in A549 cells. The overall synergy values show that over the entire response surface, synergy was comparable between the two cell lines, H460 $175 \mu \mathrm{M}^{2} \%$ and A549 cells $193 \mu \mathrm{m}^{2} \%$ at the $95 \%$ confidence interval.

\section{XAC 1396-11 and vinorelbine induce schedule-dependent apoptotic cell death of $\mathrm{H} 460$ cells}

To determine whether the observed synergy between XAC 1396-11 and vinorelbine resulted from enhanced apoptosis, $\mathrm{H} 460$ cells were exposed to either of the single agents at low concentrations that did not result in a significant elevation in cleaved caspase- 3 or PARP. The combination of XAC 1396-11 and vinorelbine, at the same low concentrations, increased cleaved caspase- 3 and induced PARP cleavage (Figure 4A arrow). Significantly, higher apoptotic index values were seen for the combination than either single agent alone $(P<0.01)$, data not shown. This process could be reversed by the addition of a pan-caspase inhibitor providing further evidence that synergy is mediated through apoptosis. Immunoblot analysis shows that in cells treated with low concentrations of XAC 1396-11, no compensatory increases the levels of XIAP, c-IAP1, c-IAP2 and Survivin were observed (confirmed by densitometry measurements).

\section{Schedule dependency of vinorelbine and XAC 1396-11 synergy}

To determine whether the sequence of drug addition impacts on resulting synergy, cells were treated for $36 \mathrm{~h}$ with XAC 1396-11, followed by removal of the supernatant, and treatment for $36 \mathrm{~h}$ with the vinorelbine, or vice versa. The CI results show that 

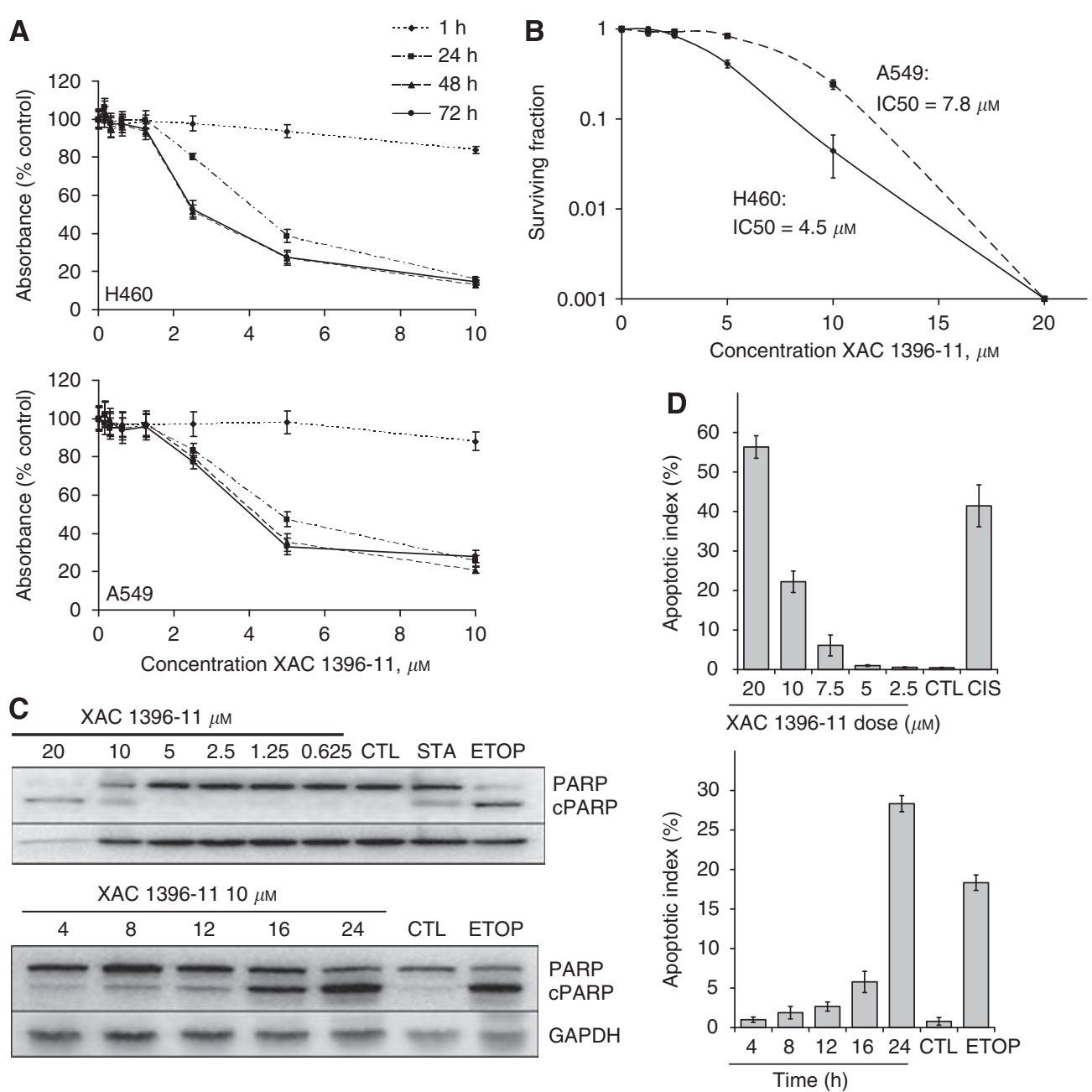

Figure 2 XAC I 396-I I induces cell death by apoptosis in NSCLC cells. (A) NSCLC cells were plated in exponential phase and treated at the indicated concentrations and times. Growth inhibition was determined by SRB assay (mean \pm s.e.m.; $n=3$ ). (B) Clonogenic survival determined after $24 \mathrm{~h}$ XAC I $396-$ $\mathrm{II}$ at the indicated concentrations. Colonies were grown for 7 days before the plates were fixed. Surviving fraction was calculated as the number of colonies in the test condition divided by the number of colonies in the untreated well and plotted logarithmically against drug dose (mean \pm s.e.m.; $n=3)$. (C) $H 460$ cells were treated for $24 \mathrm{~h}$ at the indicated concentrations (upper panel) or at $10 \mu \mathrm{M}$ XAC |396-I I for the times (h) shown (lower panel), before lysates were prepared for immunoblot analysis. Membranes were probed with antibodies specific for full-length or cleaved ('c' as indicated) PARP and for GAPDH. (D) $\mathrm{H} 460$ cells were treated as for $(\mathbf{C})$, but fixed and DAPI stained for assessing percentage apoptotic nuclear morphology (mean \pm s.e.m.; $n=3$ ). $\mathrm{CTL}=$ control; $\mathrm{ETOP}=$ etoposide $20 \mu \mathrm{M} ; \mathrm{STA}=$ staurosporine $\mathrm{I} \mu \mathrm{M}$; CIS = cisplatin $50 \mu \mathrm{M}$.

Table I XAC |396-I| synergizes with cytotoxic anticancer drugs in $\mathrm{H} 460$ and $\mathrm{A} 549$ cell lines

\begin{tabular}{lllll}
\hline $\begin{array}{l}\text { Cell } \\
\text { line }\end{array}$ & $\begin{array}{l}\text { XAC I396-I } \\
\text { Combination }\end{array}$ & \multicolumn{1}{c}{$\mathbf{I C}_{\mathbf{2 5}}$} & \multicolumn{1}{c}{$\mathbf{I C}_{\mathbf{5 0}}$} & \multicolumn{1}{c}{$\mathbf{I C}_{\mathbf{7 5}}$} \\
\hline $\mathrm{H} 460$ & Vinorelbine & $0.40(+++)$ & $0.37(+++)$ & $0.35(+++)$ \\
$\mathrm{H} 460$ & Cisplatin & $0.80(++)$ & $0.74(++)$ & $0.50(+++)$ \\
$\mathrm{H} 460$ & Vinorelbine and cisplatin & $0.65(+++)$ & $0.70(++)$ & $0.74(++)$ \\
$\mathrm{H} 460$ & Gemcitabine & $0.72(++)$ & $0.74(++)$ & $0.87(+)$ \\
H460 & Taxotere & $1.02( \pm)$ & $1.09( \pm)$ & $1.11(-)$ \\
A549 & Vinorelbine & $0.36(+++)$ & $0.24(++++)$ & $0.33(+++)$ \\
A549 & Cisplatin & $0.84(++)$ & $0.79(++)$ & $0.73(++)$ \\
A549 & Vinorelbine and cisplatin & $0.69(+++)$ & $0.78(++)$ & $0.85(+)$ \\
A549 & Gemcitabine & $0.78(++)$ & $0.93( \pm)$ & $1.09( \pm)$ \\
A549 & Taxotere & $1.08( \pm)$ & $1.04( \pm)$ & $1.02( \pm)$ \\
\hline
\end{tabular}

Non-small cell lung cancer (NSCLC) cells were treated for $72 \mathrm{~h}$ with equipotent concentrations of XAC I396-II and the cytotoxic, before being fixed and analysed by SRB assay. Six concentrations of drugs were used starting at $4 \times 1 C_{50}$ values and covering the dose-effect curve. Additivity is taken to be in the range $\mathrm{Cl}=0.9-1$. I

$( \pm)$, synergy $\mathrm{Cl}<0.9(+)$ and antagonism $\mathrm{Cl}>\mathrm{I} . \mathrm{l}(-)$. treatment with XAC 1396-11 followed by vinorelbine is more synergistic than sequencing these agents in the reverse order, or for $72 \mathrm{~h}$ co-treatment, (Figure $4 \mathrm{~B}$ ).

\section{XAC 1396-11, cisplatin and vinorelbine are a synergistic drug regimen}

As cisplatin and vinorelbine are conventionally used together in the treatment of NSCLC, the impact of both cytotoxics with XAC 1396-11 was investigated (Table 1). The three drug combination showed greatest synergy at low concentrations $\mathrm{IC}_{25}$ consistent with the hypothesis that XAC 1396-11 can sensitise to clinically relevant cytotoxics, potentially permitting dosereduction while maintaining efficacy.

\section{DISCUSSION}

NSCLC is the most prevalent cancer worldwide yet mortality rates remain dismal. Although some progress has been made in the 
A

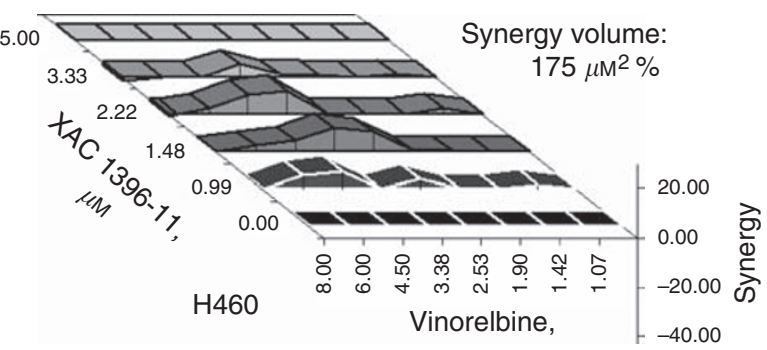

$\mathrm{nM}$

B

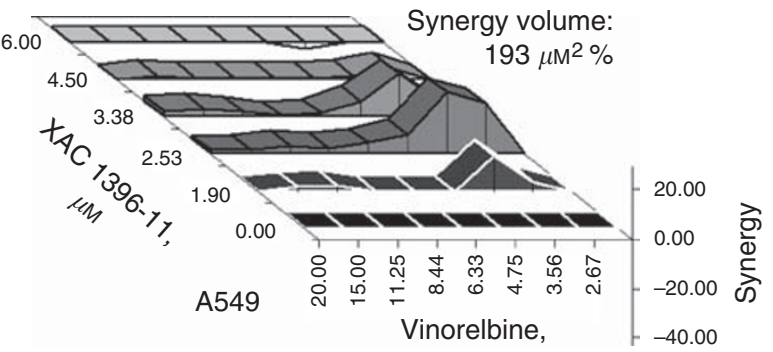

$\mathrm{nM}$

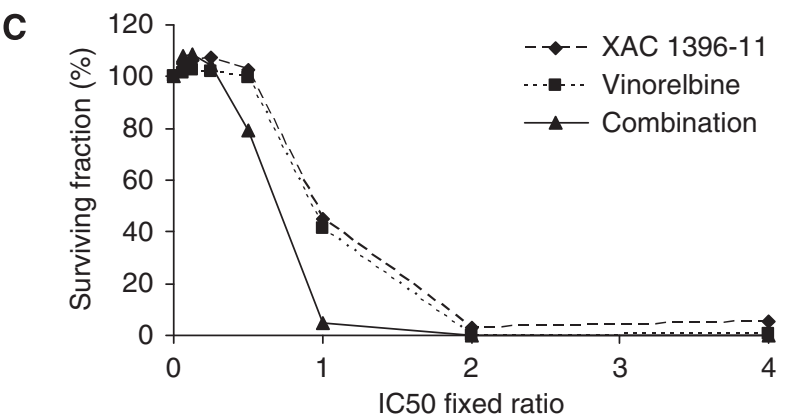

Figure 3 XAC |396-II synergises with cytotoxic anticancer drugs in H460 and A549 cell lines. (A) H460 (A) and A549 (B) cells were treated in a five by eight checkerboard matrix of XAC |396-I|/cytotoxic combinations, plus each drug tested alone, covering the concentrationeffect curve. After $72 \mathrm{~h}$, plates were fixed and analysed by SRB before determining synergy using the three-dimensional Pritchard and Shipman model. Positive values (above the baseline) represent synergy; negative values (below the surface) are antagonistic. The overall synergy value $\left(\mu \mathrm{M}^{2} \%\right)$ is shown at the $95 \%$ confidence interval. (C) H460 cells were treated as in Table I. The $x$ axis shows the fixed ratio used in the combination with equipotent concentrations of the single agents. The combination arm shifts the concentration-effect curve to the left. All experiments were repeated in triplicate, error bars show s.e.m.

development of targeted agents for NSCLC, palliative chemotherapy remains the mainstay of treatment for the majority of patients who present with advanced metastatic disease and who often have co-morbidities making them unfit for radical surgery or chemo-radiation. After a large-scale combinatorial screen of chemical libraries, Schimmer et al (2004a) discovered multiple small molecules with XIAP inhibitory activity, including the compound XAC 1396-11. The preclinical effects of these XIAP inhibitors have been confirmed by their ability to induce apoptosis of both haematologic and solid tumour cell lines in vitro, and their ability to sensitise cancer cells to chemotherapeutic drugs (Schimmer et al, 2004a; Carter et al, 2005). Our rationale was to investigate whether XIAP inhibition with XAC 1396-11, in NSCLC, could sensitise to chemotherapy with the potential to dose-reduce cytotoxic treatment, thus preventing chemotherapy-induced toxicity but maintaining therapeutic efficacy.

This is the first report to explore the efficacy of a small molecule XIAP antagonist in NSCLC. Using XAC 1396-11 in combination
A

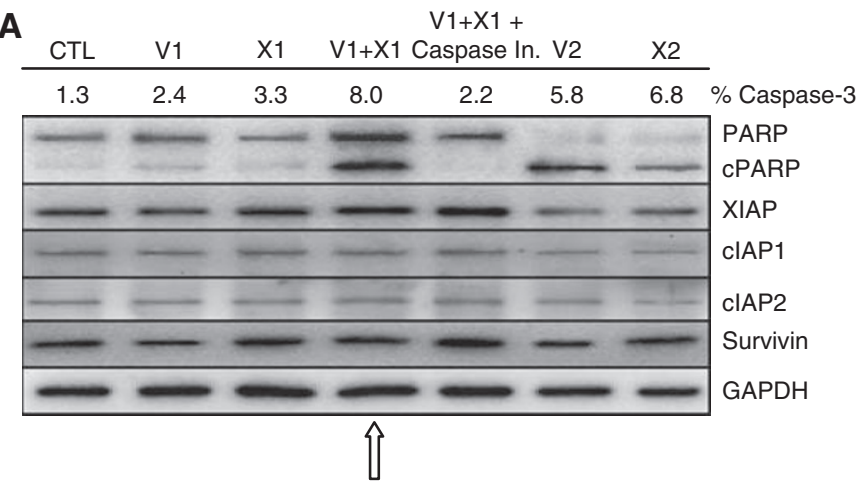

B

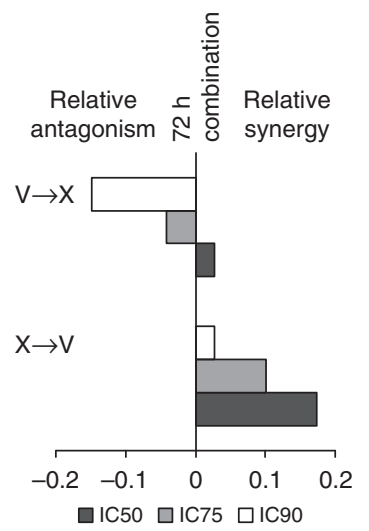

Figure 4 Combination of XAC |396-I| and vinorelbine synergistically induces apoptosis of NSCLC cells. (A) H460 cells were treated for $72 \mathrm{~h}$ with vinorelbine, XAC |396- I | or the combination \pm pan-caspase inhibitor (caspase In.), at the indicated concentrations below. Lysates were then prepared for immunoblot analysis using antibodies recognising PARP (fulllength and cleaved 'c' PARP), XIAP, CIAPI, CIAP2, Survivin and GAPDH. Low concentrations of the single agents failed to induce PARP cleavage, whereas combination treatment provoked PARP cleavage (arrow). $\mathrm{VI}=$ vinorelbine $2.5 \mathrm{nM} ; X|=X A C| 396-|| \mid 5 \mu \mathrm{M}$; Caspase In. $=50 \mu \mathrm{M}$; $\mathrm{V} 2=$ vinorelbine $10 \mathrm{nM} ; \mathrm{X} 2=\mathrm{XAC}|396-||| 10 \mu \mathrm{M} ; C T L=$ control $(\mathbf{B})$. $\mathrm{H} 460$ cells were treated for $36 \mathrm{~h}$ with the first agent followed by removal of the supernatant and treatment for $36 \mathrm{~h}$ with the second agent, covering the concentration-effect curve $(V=$ vinorelbine; $X=X A C$ |396-II). The plates were fixed and growth inhibition was determined by SRB. The $\mathrm{Cl}$ results at the $I C_{25}, I C_{50}$ and $I C_{75}$ are shown. All experiments were repeated in triplicate, error bars show s.e.m.

with cytotoxics in vitro, evidence is presented that XIAP inhibition sensitises cancer cells to death induced by a variety of chemotherapeutic agents. This cytotoxic effect was most pronounced with vinorelbine in H460 and A549 NSCLC lines. Furthermore, the synergy data for the XAC 1396-11/vinorelbine combination are consistent using two differing methodologies in which the mechanism of synergy is through enhanced apoptosis, as shown by cleavage of caspase- 3 and PARP and by the reversal of synergy using a pan-caspase inhibitor. Vinorelbine, a Vinca alkaloid, interferes with microtubule assembly leading to mitotic arrest and/or cell death. It is approved for use as a single agent or in combination with platinum in the first line treatment of stage III or IV NSCLC. Our results suggest the addition of XAC 1396-11 to vinorelbine alone or in combination with a platinum agent may sensitise patients to the effects of chemotherapy. The drug sequencing experiments reported here data support the notion that vinorelbine is most effective at inducing apoptosis once the 'apoptotic brake' has been removed with XAC 1396-11. The data presented show that at every inhibitory concentration, that is $\mathrm{IC}_{25}$, $\mathrm{IC}_{50}$ and $\mathrm{IC}_{75}$, pretreatment with XAC 1396-11 followed by 
vinorelbine was more synergistic than the reverse sequence. This supports the concept that blockade of an endogenous apoptosis suppressor allows drug damage to be coupled to the engagement of apoptosis.

XAC 1396-11 targets near the BIR2 domain of XIAP (Schimmer et al, 2004a), which is responsible for inhibition of caspases-3 and -7, down-stream effector proteases operating at the convergence of both intrinsic and extrinsic apoptotic pathways. However, it is not clear whether blocking BIR2 to mediate release of effector caspases, or selectively targeting the BIR3 domain, which binds to inhibit the upstream initiator protease caspase- 9 , is the more effective strategy (Srinivasula et al, 2001a; Nikolovska-Coleska et al, 2004; Sun et al, 2006). It has been shown in H460 cells that disruption of XIAP-caspase-9 binding with SMAC mimetics restored apoptosis (Yang et al, 2003). However, intratumoural injections of SMAC mimetics alone in an H460 xenograft model did not have any apparent tumour-suppressive effect. Theoretically, SMIs that target both the BIR2 and BIR3 domains should be most efficacious. In interpreting the results of experiments with IAP-family proteins, it should be noted that complex effects have been documented beyond reversal of caspase inhibition. For example, compounds that target SMAC-binding sites on BIR domains activate the intrinsic E3 ligase activity of IAPs, causing their self-ubiquitinylation and subsequent proteasome-dependent degradation (Zhang et al, 2004). Compound-triggered clearance of cIAP1 and cIAP2 from cells causes accumulation of NIK and induces other events that stimulate NF- $\kappa \mathrm{B}$ activity and induce TNF $\alpha$ production (Varfolomeev et al, 2007). Recently, it has also been shown that efficient induction of cell death by SMIs requires antagonism of both c-IAPs and XIAP proteins but whether this pan-IAP inhibition is associated with higher toxicities remains untested (Ndubaku et al, 2009). Further analysis of the phenylurea-series XIAP inhibitors, such as XAC 1396-11, is required to ascertain their effects on caspase-independent aspects of XIAP biology (such as NF- $\kappa$ B activation mediated by TAK/TAB binding) and to elucidate whether they target other members of the IAP or have off-target activities that contribute to their cytotoxic activity.

Another approach to targeting XIAP is the use of small interfering RNA (siRNA) to induce degradation of the target mRNA. XIAP siRNA enhances sensitivity to methotrexate in hepatoma (Chen et al, 2006), to cisplatin, fluorouracil and etoposide in oesophageal carcinoma (Zhang et al, 2007), to TRAIL in melanoma, breast cancer and pancreatic cancer (Chawla-Sarkar et al, 2004; McManus et al, 2004) and also sensitises pancreatic cancer cell lines to $\gamma$-irradiation (Giagkousiklidis et al, 2007). The XIAP siRNA approach confirmed the validity of XIAP as a

\section{REFERENCES}

Berezovskaya O, Schimmer AD, Glinskii AB, Pinilla C, Hoffman RM, Reed JC, Glinsky GV (2005) Increased expression of apoptosis inhibitor protein XIAP contributes to anoikis resistance of circulating human prostate cancer metastasis precursor cells. Cancer Res 65: 2378-2386

Cao C, Mu Y, Hallahan DE, Lu B (2004) XIAP and survivin as therapeutic targets for radiation sensitization in preclinical models of lung cancer. Oncogene 23: $7047-7052$

Carter BZ, Gronda M, Wang Z, Welsh K, Pinilla C, Andreeff M, Schober WD, Nefzi A, Pond GR, Mawji IA, Houghten RA, Ostresh J, Brandwein J, Minden MD, Schuh AC, Wells RA, Messner H, Chun K, Reed JC, Schimmer AD (2005) Small-molecule XIAP inhibitors derepress downstream effector caspases and induce apoptosis of acute myeloid leukemia cells. Blood 105: 4043-4050

Chawla-Sarkar M, Bae SI, Reu FJ, Jacobs BS, Lindner DJ, Borden EC (2004) Downregulation of Bcl-2, FLIP or IAPs (XIAP and survivin) by siRNAs sensitizes resistant melanoma cells to Apo2L/TRAIL-induced apoptosis. Cell Death Differ 11: 915-923 therapeutic target but the problem of in vivo delivery of siRNAs regimens still must be overcome.

An alternative nucleic acid-directed strategy for targeting XIAP is the use of ASOs that form a duplex with native mRNA, inducing its degradation through RNAase $\mathrm{H}$ enzymes. The undertaking of this study was encouraged by reports that XIAP downregulation in lung cancer using ASOs can be synergistic with other therapeutic modalities used in the treatment of the disease. XIAP ASOs have also been combined with cytotoxics (doxorubicin, paclitaxel, vinorelbine and etoposide) in $\mathrm{H} 460$ cells in vitro, showing synergy using the CI method. In H460 tumour-bearing mice, XIAP ASOs have also been combined with vinorelbine ( $\mathrm{Hu}$ et al, 2003) and $\gamma$-irradiation (Cao et al, 2004), showing a significant delay in tumour establishment and reduction in tumour volume, respectively. In addition, in vivo tumour xenograft models of prostate (PC-3), colon (LS174T) and NSCLC (H460) cancer showed that XIAP ASO was effective as a single agent (LaCasse et al, 2006). Phase I/II trial results for XIAP ASOs both as a single agent and in combination with chemotherapy in refractory/relapsed AML have recently been published using a variety of dosing schedules (AEG35156, Aegera Therapeutics Inc. Montreal, Québec, Canada) (Dean et al, 2009; Schimmer et al, 2009). AEG35156 was well tolerated in the 7-day and 3-day infusion regimens with predictable toxicities (raised hepatic enzymes, hypophosphatemia and thrombocytopenia), pharmacokinetic properties and clinical evidence of antitumour activity. These early clinical data bode well for SMIs targeting XIAP that are approaching the clinic.

In summary, the results presented here are the first to address the potential therapeutic role of XAC 1396-11, an SMI of XIAP for NSCLC, and the possibility for synergy with cytotoxics commonly used in the treatment of the disease. Using two independent methods, XAC 1396-11 was shown to synergise with clinically used cytotoxic agents in NSCLC cell lines and evidence was obtained that the mechanism of synergy is through increased apoptosis. Pretreatment with the XIAP-targeting drug produced optimal synergy. Thus, combining small molecule therapeutics targeting apoptosis regulators, such as XIAP with conventional cytotoxic agents, promises to improve the management of highly resistant malignancies such as lung cancer, warranting further pre-clinical in vivo studies to evaluate the potential of such combination therapies.

\section{ACKNOWLEDGEMENTS}

E Dean was funded by a Cancer Research UK Studentship (C237/ A7819). C Dive is funded by CR-UK (C147/A6058).
Chen J, Xiao XQ, Deng CM, Su XS, Li GY (2006) Downregulation of xIAP expression by small interfering RNA inhibits cellular viability and increases chemosensitivity to methotrexate in human hepatoma cell line HepG2. J Chemother 18: 525-531

Chou T, Talalay P (1977) A simple gerneralized equation for the analysis of multiple inhbitions of Michaelis-Menten kinetic systems. J Biol Chem 252: $6438-6442$

CR-UK (2009) CancerStats Key Facts on Lung Cancer and Smoking, http://info.cancerresearchuk.org/cancerstats/types/lung/ Retrieved on 04/10/2009

Dean E, Jodrell D, Connolly K, Danson S, Jolivet J, Durkin J, Morris S, Jowle D, Ward T, Cummings J, Dickinson G, Aarons L, Lacasse E, Robson L, Dive C, Ranson M (2009) Phase I Trial of AEG35156 administered as a 7-day and 3-day continuous intravenous infusion in patients with advanced refractory cancer. J Clin Oncol 27: 1660-1666

Deveraux QL, Takahashi R, Salvesen GS, Reed JC (1997) X-linked IAP is a direct inhibitor of cell-death proteases. Nature 388: $300-304$ 
Du C, Fang M, Li Y, Li L, Wang X (2000) Smac, a mitochondrial protein that promotes cytochrome c-dependent caspase activation by eliminating IAP inhibition. Cell 102: $33-42$

Giagkousiklidis S, Vellanki SH, Debatin KM, Fulda S (2007) Sensitization of pancreatic carcinoma cells for gamma-irradiation-induced apoptosis by XIAP inhibition. Oncogene 26: $7006-7016$

Hanahan D, Weinberg RA (2000) The hallmarks of cancer. Cell 100: 57-70

Harlin H, Birkey Reffey S, Duckett CS, Lindsten T, Thompson CB (2001) Characterization of XIAP-deficient mice. Mol Cell Biol 21: $3604-3608$

Holcik M, Yeh C, Korneluk RG, Chow T (2000) Translational upregulation of X-linked inhibitor of apoptosis (XIAP) increases resistance to radiation induced cell death. Oncogene 19: 4174-4177

Hu Y, Cherton-Horvat G, Dragowska V, Baird S, Korneluk RG, Durkin JP, Mayer LD, LaCasse EC (2003) Antisense oligonucleotides targeting XIAP induce apoptosis and enhance chemotherapeutic activity against human lung cancer cells in vitro and in vivo. Clin Cancer Res 9: 2826-2836

Karikari CA, Roy I, Tryggestad E, Feldmann G, Pinilla C, Welsh K, Reed JC, Armour EP, Wong J, Herman J, Rakheja D, Maitra A (2007) Targeting the apoptotic machinery in pancreatic cancers using small-molecule antagonists of the X-linked inhibitor of apoptosis protein. Mol Cancer Ther 6: $957-966$

Kater AP, Dicker F, Mangiola M, Welsh K, Houghten R, Ostresh J, Nefzi A, Reed JC, Pinilla C, Kipps TJ (2005) Inhibitors of XIAP sensitize CD40activated chronic lymphocytic leukemia cells to CD95-mediated apoptosis. Blood 106: $1742-1748$

LaCasse EC, Cherton-Horvat GG, Hewitt KE, Jerome LJ, Morris SJ, Kandimalla ER, Yu D, Wang $\mathrm{H}$, Wang W, Zhang R, Agrawal S, Gillard JW, Durkin JP (2006) Preclinical characterization of AEG35156/ GEM 640, a second-generation antisense oligonucleotide targeting X-linked inhibitor of apoptosis. Clin Cancer Res 12: $5231-5241$

Li L, Thomas RM, Suzuki H, De Brabander JK, Wang X, Harran PG (2004) A small molecule Smac mimic potentiates TRAIL- and TNFalphamediated cell death. Science 305: $1471-1474$

Liston P, Fong WG, Kelly NL, Toji S, Miyazaki T, Conte D, Tamai K, Craig CG, McBurney MW, Korneluk RG (2001) Identification of XAF1 as an antagonist of XIAP anti-Caspase activity. Nat Cell Biol 3: 128-133

McManus DC, Lefebvre CA, Cherton-Horvat G, St-Jean M, Kandimalla ER, Agrawal S, Morris SJ, Durkin JP, Lacasse EC (2004) Loss of XIAP protein expression by RNAi and antisense approaches sensitizes cancer cells to functionally diverse chemotherapeutics. Oncogene 23: 8105-8117

Ndubaku C, Varfolomeev E, Wang L, Zobel K, Lau K, Elliott LO, Maurer B, Fedorova AV, Dynek JN, Koehler M, Hymowitz SG, Tsui V, Deshayes K, Fairbrother WJ, Flygare JA, Vucic D (2009) Antagonism of c-IAP and XIAP proteins is required for efficient induction of cell death by smallmolecule IAP antagonists. ACS Chem Biol 4: 557-566

Nikolovska-Coleska Z, Xu L, Hu Z, Tomita Y, Li P, Roller PP, Wang R, Fang X, Guo R, Zhang M, Lippman ME, Yang D, Wang S (2004) Discovery of embelin as a cell-permeable, small-molecular weight inhibitor of XIAP through structure-based computational screening of a traditional herbal medicine three-dimensional structure database. J Med Chem 47: 2430-2440

Oost TK, Sun C, Armstrong RC, Al-Assaad AS, Betz SF, Deckwerth TL, Ding $\mathrm{H}$, Elmore SW, Meadows RP, Olejniczak ET, Oleksijew A, Oltersdorf T, Rosenberg SH, Shoemaker AR, Tomaselli KJ, Zou H, Fesik SW (2004) Discovery of potent antagonists of the antiapoptotic protein XIAP for the treatment of cancer. J Med Chem 47: 4417-4426

Pritchard M, Shipman CJ (1990) A three-dimensional model to analyze drug-drug interactions. Antiviral Res 14: 181-206

Reed JC (2003) Apoptosis-targeted therapies for cancer. Cancer Cell 3: $17-22$

Sasaki H, Sheng Y, Kotsuji F, Tsang BK (2000) Down-regulation of X-linked inhibitor of apoptosis protein induces apoptosis in chemoresistant human ovarian cancer cells. Cancer Res 60: 5659-5666

Schimmer AD, Estey EH, Borthakur G, Carter BZ, Schiller GJ, Tallman MS, Altman JK, Karp JE, Kassis J, Hedley DW, Brandwein J, Xu W, Mak DH,
Lacasse E, Jacob C, Morris SJ, Jolivet J, Andreeff M (2009) Phase I/II Trial of AEG35156 X-linked inhibitor of apoptosis protein antisense oligonucleotide combined with idarubicin and cytarabine in patients with relapsed or primary refractory acute myeloid leukemia. J Clin Oncol 27: $4741-4746$

Schimmer AD, Welsh K, Pinilla C, Wang Z, Krajewska M, Bonneau MJ, Pedersen IM, Kitada S, Scott FL, Bailly-Maitre B, Glinsky G, Scudiero D, Sausville E, Salvesen G, Nefzi A, Ostresh JM, Houghten RA, Reed JC (2004a) Small-molecule antagonists of apoptosis suppressor XIAP exhibit broad antitumor activity. Cancer Cell 5: 25-35

Schimmer AD, Welsh K, Pinilla C, Wang Z, Krajewska M, Bonneau MJ, Pedersen IM, Kitada S, Scott FL, Bailly-Maitre B, Glinsky G, Scudiero D, Sausville E, Salvesen G, Nefzi A, Ostresh JM, Houghten RA, Reed JC (2004b) Small-molecule antagonists of apoptosis suppressor XIAP exhibit broad antitumour activity. Cancer Cell 5: 25-35

Scott FL, Denault JB, Riedl SJ, Shin H, Renatus M, Salvesen GS (2005) XIAP inhibits caspase- 3 and -7 using two binding sites: evolutionarily conserved mechanism of IAPs. EMBO J 24: 645-655

Spira A, Ettinger DS (2004) Multidisciplinary management of lung cancer. $N$ Engl J Med 350: 379-392

Srinivasula SM, Hegde R, Saleh A, Datta P, Shiozaki E, Chai J, Lee RA, Robbins PD, Fernandes-Alnemri T, Shi Y, Alnemri ES (2001a) A conserved XIAP-interaction motif in caspase-9 and Smac/DIABLO regulates caspase activity and apoptosis. Nature 410: 112-116

Srinivasula SM, Hegde R, Saleh A, Datta P, Shiozaki E, Chai J, Lee RA, Robbins PD, Fernandes-Alnemri T, Shi Y, Alnemri ES (2001b) A conserved XIAP-interaction motif in caspase-9 and Smac/DIABLO regulates caspase activity and apoptosis. Nature 410: 112-116 Erratum in Nature 2001 June 28; 411(6841):1081

Sun H, Nikolovska-Coleska Z, Lu J, Qiu S, Yang CY, Gao W, Meagher J, Stuckey J, Wang S (2006) Design, synthesis, and evaluation of a potent, cell-permeable, conformationally constrained second mitochondria derived activator of caspase (Smac) mimetic. J Med Chem 49: 7916-7920

Tamm I, Kornblau SM, Segall H, Krajewski S, Welsh K, Kitada S, Scudiero DA, Tudor G, Qui YH, Monks A, Andreeff M, Reed JC (2000) Expression and prognostic significance of IAP-family genes in human cancer and myeloid leukemias. Clin Cancer Res 6: 1796-1803

Varfolomeev E, Blankenship JW, Wayson SM, Fedorova AV, Kayagaki N, Garg P, Zobel K, Dynek JN, Elliott LO, Wallweber HJ, Flygare JA, Fairbrother WJ, Deshayes K, Dixit VM, Vucic D (2007) IAP antagonists induce autoubiquitination of c-IAPs, NF-kappaB activation, and TNFalpha-dependent apoptosis. Cell 131: 669-681

Verhagen AM, Ekert PG, Pakusch M, Silke J, Connolly LM, Reid GE, Moritz RL, Simpson RJ, Vaux DL (2000) Identification of DIABLO, a mammalian protein that promotes apoptosis by binding to and antagonizing IAP proteins. Cell 102: $43-53$

Vichai V, Kirtikara K (2006) Sulforhodamine B colorimetric assay for cytotoxicity screening. Nat Protoc 1: $1112-1116$

Wang Z, Cuddy M, Samuel T, Welsh K, Schimmer A, Hanaii F, Houghten R, Pinilla C, Reed JC (2004) Cellular, biochemical, and genetic analysis of mechanism of small molecule IAP inhibitors. J Biol Chem 279: $48168-48176$

Wilkinson JC, Cepero E, Boise LH, Duckett CS (2004) Upstream regulatory role for XIAP in receptor-mediated apoptosis. Mol Cell Biol 24: $7003-7014$

Yang L, Mashima T, Sato S, Mochizuki M, Sakamoto H, Yamori T, Oh-Hara T, Tsuruo T (2003) Predominant suppression of apoptosome by inhibitor of apoptosis protein in non-small cell lung cancer $\mathrm{H} 460$ cells: therapeutic effect of a novel polyarginine-conjugated Smac peptide. Cancer Res 63: 831-837

Zhang HG, Wang J, Yang X, Hsu HC, Mountz JD (2004) Regulation of apoptosis proteins in cancer cells by ubiquitin. Oncogene 23: 2009-2015

Zhang S, Ding F, Luo A, Chen A, Yu Z, Ren S, Liu Z, Zhang L (2007) XIAP is highly expressed in esophageal cancer and its downregulation by RNAi sensitizes esophageal carcinoma cell lines to chemotherapeutics. Cancer Biol Ther 6: $973-980$ 